\title{
Finite Element Method for Dynamic Response in Enclosed Gear-Driven System
}

\author{
Bin-Hui Han ${ }^{*}, 1,2$, Da-Gang Sun ${ }^{1}$, Zhan-Long Li $^{3}$, Yong Song ${ }^{1}$ and Jian-Guang Zhang ${ }^{2}$ \\ ${ }^{I}$ College of Mechanical Engineering, Taiyuan University of Science and Technology, Taiyuan, Shanxi 030024, China \\ ${ }^{2}$ Tai Yuan Institute Co., Ltd. of China Coal Technology and Engineering Group, Taiyuan, Shanxi 030006, China \\ ${ }^{3}$ Faculty of Mechanical Instrumental Engineering, Xi'an University of Technology, Xi'an 710048, China
}

\begin{abstract}
The theoretical solving of dynamic analysis on the enclosed gear-driven system is complicated, and only the surface vibration data can be tested in the experiment. In view of this, 3D modeling is carried out on a given secondary planet reducer to create a finite element model and perform finite element modal analysis. Via the modal test, the correctness of the simulation is verified. Also, ANSYS transient dynamics analysis (Full) is utilized and nonlinear factors (e.g., time-varying mesh stiffness, composite mesh error, gear backlash, and damping ratio etc.) are taken into account to make a comparison between dynamic simulation and bench test. Research results show that the first six natural frequencies in the finite element method (FEM) are quite approximate to test results, and the maximum error ratio is $8.12 \%$, implying that the mode of vibration is identical. Moreover, the error is small between the results of the dynamic simulation and average acceleration of vibration in bench test, indicating that the vibration rules are basically consistent. Based on that, the next step is to acquire the vibration acceleration and gear ring meshing point's stress variation curve at the input end and output end, which tally with the project's actualities. Such a method helps to cover the test method's shortages in analysis of internal vibration response.
\end{abstract}

Keywords: Dynamic simulation, Enclosed gear drive, Finite element, Vibration test, ANSYS workbench, FEM model.

\section{INTRODUCTION}

Since the gears in enclosed gear-driven systems run in a tightly-enclosed and precisely-machined case, they have benefits of good lubrication, excellent protection and clean working environment. Thereby they are extensively used by precise driving parts of agricultural machinery, machine tools, and automobiles etc. However, due to the system's enclosed environment, it is difficult to overcome driving problems, and to study the system's vibration noise mechanism and take effective control actions [1].

Planetary gear transmission features high driving efficiency, small size, large speed ratio, and are relatively light weight. They have a relatively complicated drive mode in terms of the enclosed drive. In transmission, meshing impact arising from meshing surface and its radiation are the dominant direct exciting source taking large proportion of responsibility for vibration and noise hazard and gear failure [2]. For a long time, academics and researchers carried out lots of valuable surveys of planet gear transmission, and the focus changes from statistical analysis [3] and temperature field simulation analysis [4] to dynamic characteristics analysis [5-11]. In most studies, academics simplify and presume the theoretical model, create oscillatory differential equation and adopt the numerical approach, in order to

\footnotetext{
*Address correspondence to this author at the College of Mechanical Engineering, Taiyuan University of Science and Technology, 66 Waliu Road, Taiyuan, Shanxi, 030024, China; Tel: +086-0351-7685903; E-mail: hbhzayy@126.com
}

acquire the system's dynamic response. As to the experimental method, the housing surface data can be easily measured, but it is difficult to acquire dynamic response of the internal parts; therefore, there are few reports on those experimental verifications about the issues mentioned above.

In view of complicated solving theory and experimental limits for planet gear transmission, the finite element model is established for a given secondary planet reducer, and a verification through modal test is made: Full method of ANSYS transient dynamics analysis is used, taking into account the nonlinear factors (e.g., time-varying mesh stiffness, composite mesh error, gear backlash, and damping ratio etc.) to obtain dynamic characteristics of the secondary planet reducer, and making a comparison with bench dynamic test. Consequently, the system internal parts' dynamic behaviors are obtained at any point and at any time, such as displacement, speed, acceleration, stress, and mesh force etc.

\section{RESEARCH IDEA}

First, the full size FEM model is produced, considering the shape, mass, surface interaction of gears and choice of actual material parameters, so as to ensure the motion accuracy of static and dynamic accordance between model and real one. Then, the FEM modal calculation results are compared with modal test results to make a preliminary judgment on the feasibility of dynamic simulation [12]. Based on this, nonlinear parameters are incorporated, including time-varying mesh stiffness, composite mesh error, 
gear backlash, and damping ratio etc. into the finite element software, and the constraint conditions and boundary conditions are set that coincide with the experiment. After that, the dynamic simulation is carried out, making a comparison between the vibration acceleration curves on the outer case surface at the first and the second stage, and the acceleration curves acquired in dynamic experiment at the corresponding positions. If the said two curves coincide with each other, it is indicated that the FEM dynamic simulation method is reliable. In the context, dynamic response at any positions of the gear system can be easily obtained through the proposed and verified FEM model without timeconsuming and expensive field and laboratory test. See Fig. (1) for the research flow chart.

\section{FINITE ELEMENT MODEL}

\subsection{D Entity Model}

A 3D model is established in exact accordance with the design drawing and configured material values with advanced meshing configuration. As for other parts, the assembling work is completed according to the matching relations to ensure that there is no interference between all parts [13-14].

Fig. (2a) indicates the studied object's structure and motion. In transmit, the housing (gear ring) is fixed, and sun gear serves as the input and planet carrier as the output. Design parameters are as follows: input rotating speed, 1470

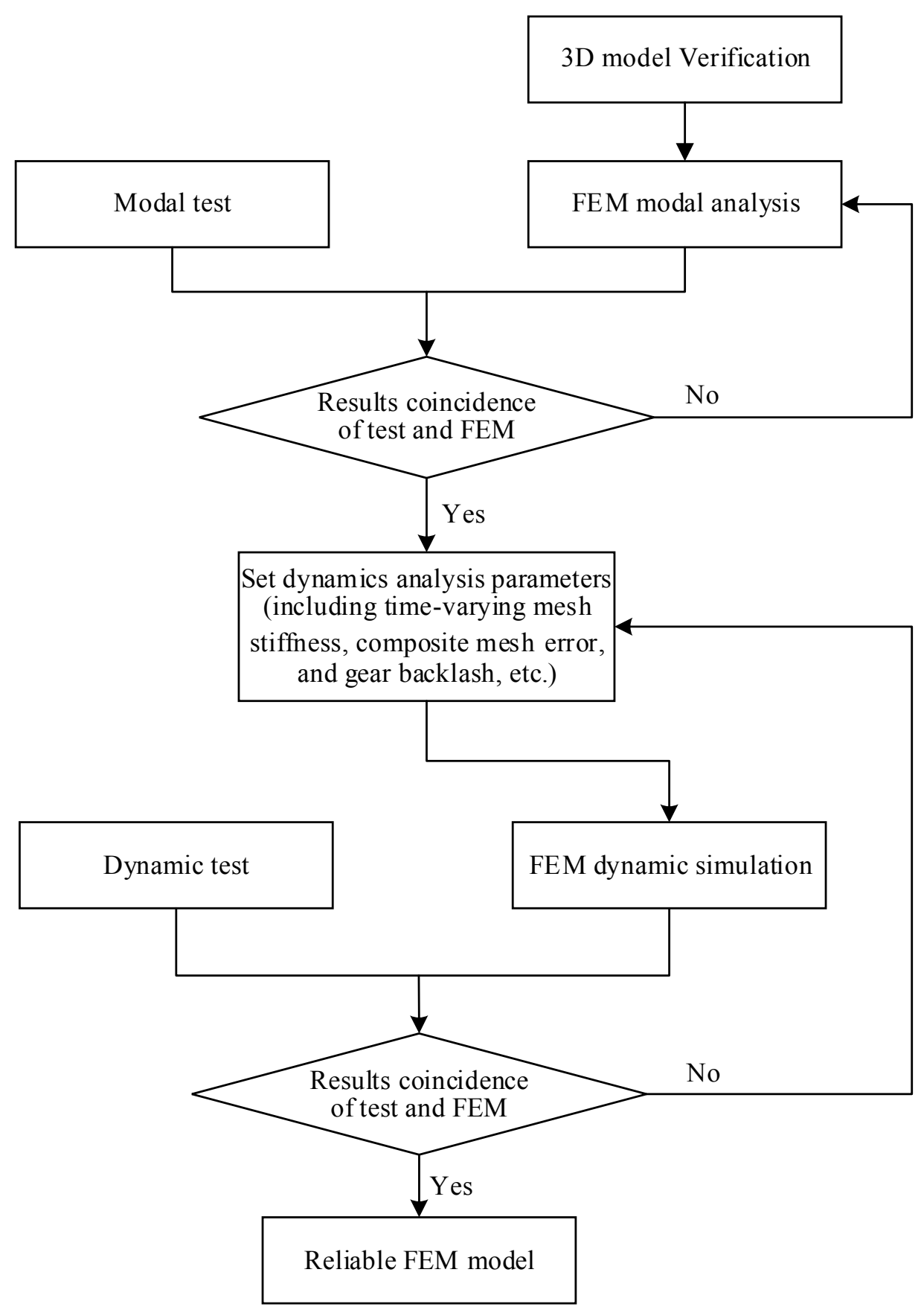

Fig. (1). The flow chart for research plan. 
rpm, and the first and second stage transmission ratios are, respectively, 5.842 and 3.9. According to the design parameters, motion simulation is exerted on the assembling body. At the input end, constant rotation motor of $1470 \mathrm{rpm}$ is exerted for $5 \mathrm{~s}$ (see Fig. 2b) for rotating speed curve acquired at interval of $0.5 \mathrm{~s}$ ). Meanwhile, the first and the second stage rotating speeds hover slightly around 1510 $\mathrm{deg} / \mathrm{s}$ and $400 \mathrm{deg} / \mathrm{s}$, respectively, which coincide with the design requirements. Besides, the drive direction is correct. Correctness of the motion simulation results offers foundation for modal analysis and dynamics analysis.

(a)

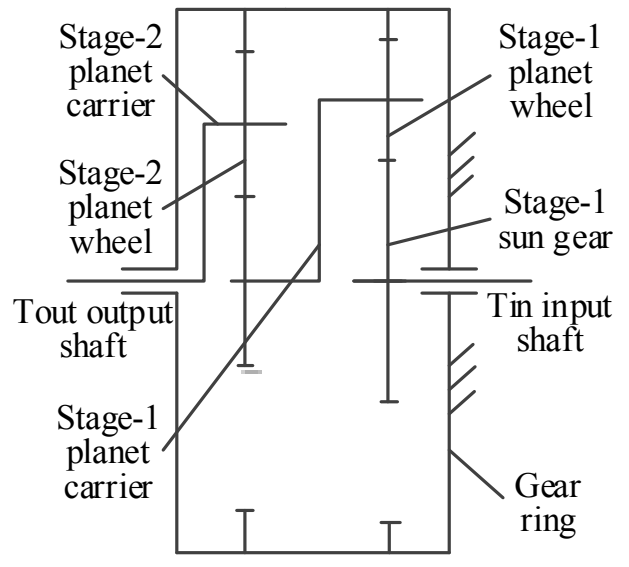

(b)

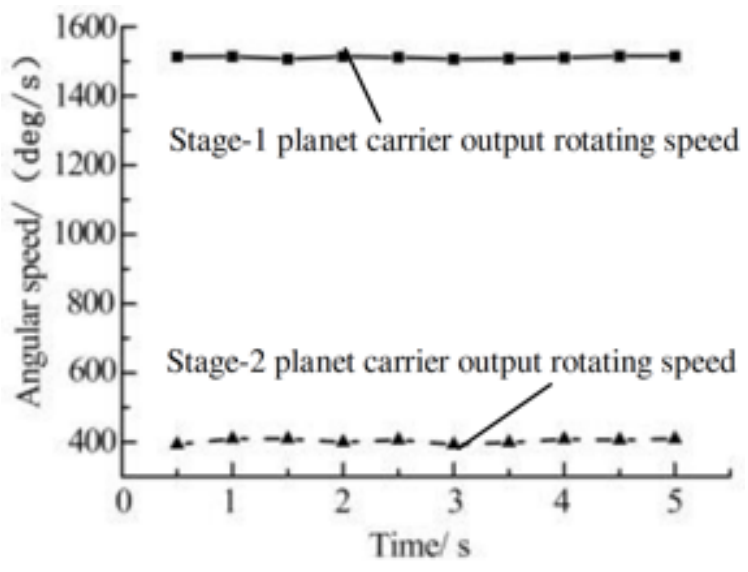

Fig. (2). Kinematic sketch and motion accuracy test for the secondary planet reducer. (a) Structural motion sketch. (b) Kinematic verification.

\subsection{Set Up Finite Element Model}

A 3D entity model is imported into ANSYS Workbench, choosing materials for parts, giving material constants such as elasticity modulus, Poisson ratio, and density parameters, and meshing the entity model with refined grids for gear teeth parts, nevertheless relatively larger meshing for the rest of the parts aiming at expediting the solving effort. After partitioning, there are total 168586 nodes and 251312 units. See Fig. (3) for finite element model. (a)

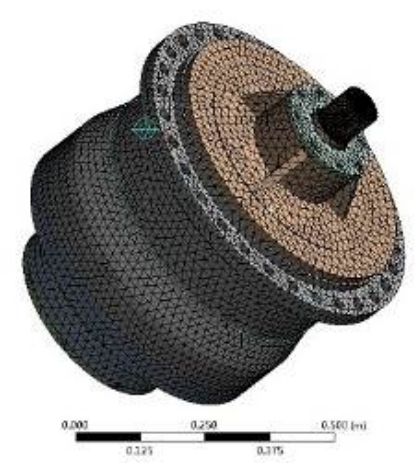

(b)

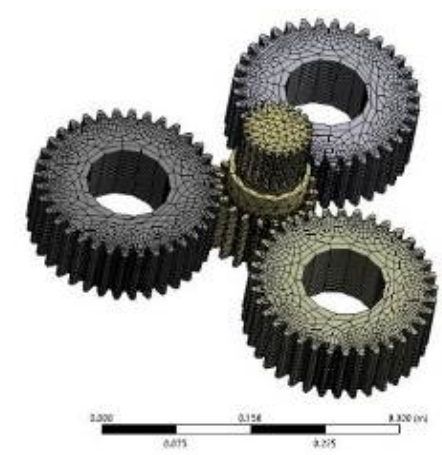

Fig. (3). The finite element model for the secondary planet reducer. (a) Assembling body finite element model. (b) Internal gear finite element model.

\section{EXPERIMENTAL VERIFICATION OF FINITE ELEMENT MODEL}

Make a comparison between results of finite element modal analysis and modal test, so as to testify the correctness of finite element dynamic model.

\subsection{Finite Element Modal Analysis}

\subsubsection{Contact}

Default contact setting in ANSYS, all belonging to bonded contact relation has to be reset by modifying the contract pair's nature. Assembling body consists of 29 parts involving 49 contact pairs. Interference fit is adopted between the bearing inner race and axle journal, and between the bearing outer race and bearing saddle bore. In addition, bolt connection is adopted between the housing and bearing seat, and between bearing seat and bearing end cover. Foresaid contact interfaces are set as "bonded", and the mating flank as frictional.

\subsubsection{Modal Analysis Results}

The constraint conditions and pre-stressing forces are applied to the FEM model, and the mode superposition method is adopted. As a result, we acquire the first 6 mode natural frequencies and modes of vibration. Of which, the 
first and second modes of vibration are axial bending, and the third and fourth modes of vibration belong to axial torsion, and the fifth and sixth modes of vibration belongs to axial compression. Modes of vibration of the same type are similar in shape. Fig. (4) illustrates the second, fourth, and sixth modes of vibration, and Table 1 lists all modes and frequencies.

(a)
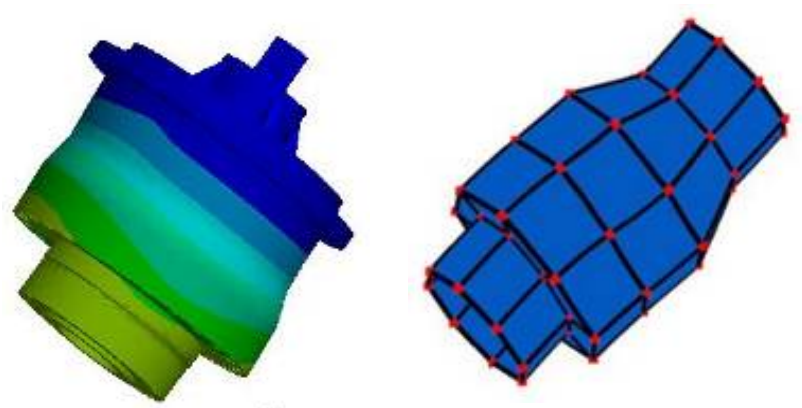

(b)
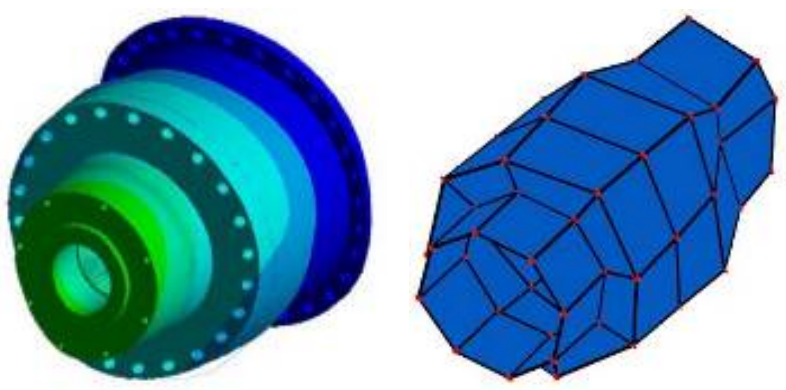

(c)
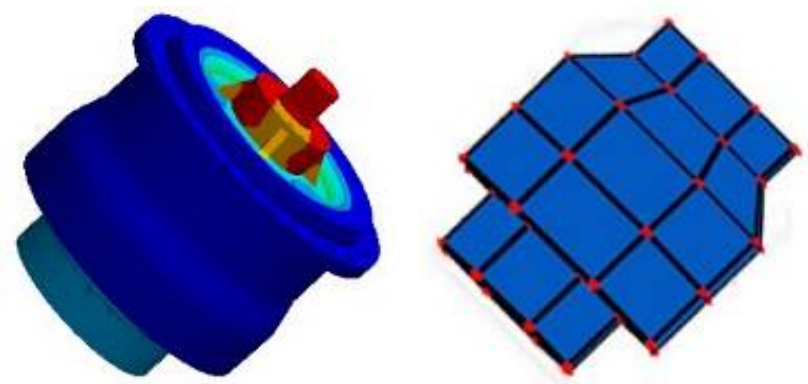

Fig. (4). Modal comparison between the finite element and experimental modal. (a) Second axial bending mode. (b) Fourth axial torsion. (c) Sixth axial compression.

\subsection{Experiment Modal Verification}

Before the experiment, drain lubricating oil in the assembling body, and suspend it with elastic hanging strips. After that, divide evenly the assembling body into 8 parts along radial direction and into 7 parts along axial direction, in order to acquire complete response data. All told, there are 56 measuring points, and every measuring point is equipped with three-way acceleration sensor involving 168 passages. Since the passages are numerous, two data collectors of the same model are adopted to acquire output data at each point. During the experiment, we employ the SIMO (single-input and multi-output) frequency response function method (dynamometry) [15] as seen in Fig. (5). Based on the principle of clearness and intuition, we require that the experiment model should be simple and easily perceived. During the experiment, we conduct real-time inspection, ensuring that coherence between excitation signal and response signal is above 0.9 to meet steady-state test conditions.

(a)

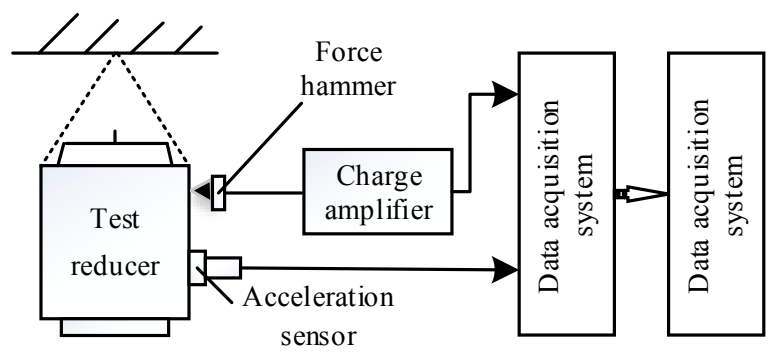

(b)

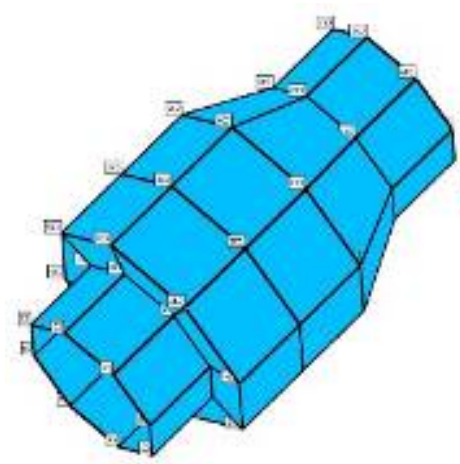

(c)

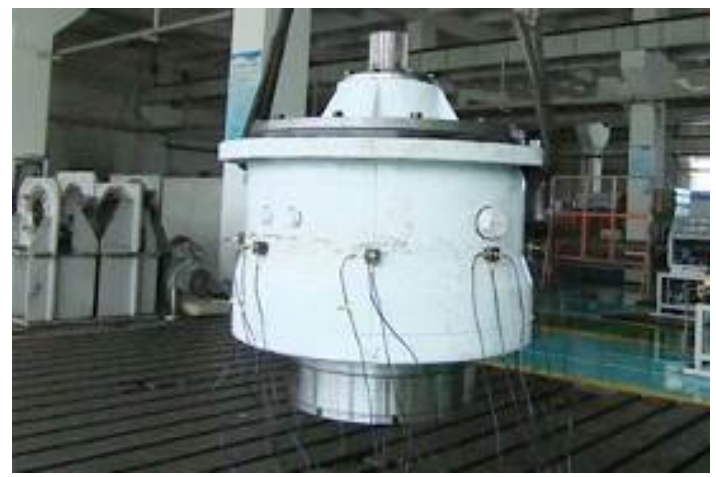

(d)

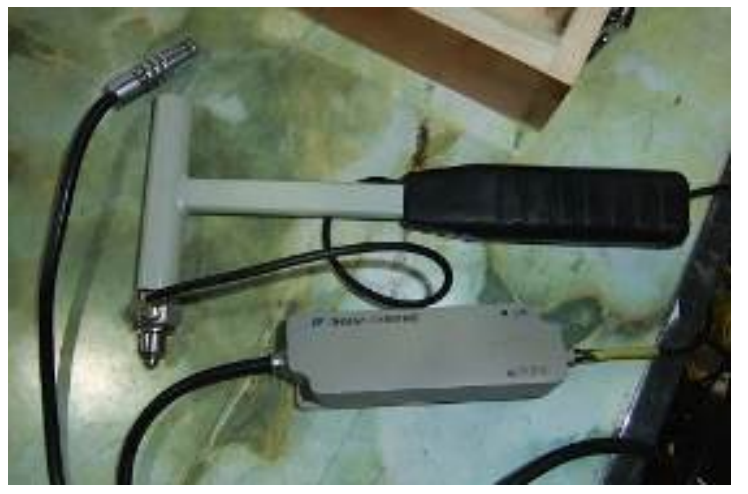

Fig. (5). Modal test system. (a) Test system sketch. (b) Experiment model. (c) Experiment field. (d) Exciting hammer and amplifier. 
After the experiment, we make judgment to the modal value according to the MAC (Modal Assurance Criterion) shown in Table 2. We can see that different modes of vibration are clearly displayed, MAC values between modes of vibration are relatively low, no "False" mode exists, and mode of vibration is accurate and reliable [16].

Table 1. Modal frequency comparison.

\begin{tabular}{|c|c|c|c|}
\hline \multirow{2}{*}{ Order } & Experiment Mode & Finite Element Mode & \multirow{2}{*}{$\begin{array}{c}\text { Relative } \\
\text { Error }\end{array}$} \\
\cline { 2 - 3 } & Frequency/Hz & Frequency/Hz & \\
\hline \hline 1 & 1200.54 & 1165.32 & $3.02 \%$ \\
\hline 2 & 1618.75 & 1725.21 & $6.17 \%$ \\
\hline 3 & 1771.29 & 1823.56 & $2.87 \%$ \\
\hline 4 & 2280.14 & 2108.96 & $8.12 \%$ \\
\hline 5 & 2540.37 & 2395.41 & $6.05 \%$ \\
\hline 6 & 3014.78 & 3201.83 & $5.84 \%$ \\
\hline
\end{tabular}

Table 2. Modal verification for MAC value.

\begin{tabular}{|c|c|c|c|c|c|c|}
\hline MAC & $\mathbf{1}$ & $\mathbf{2}$ & $\mathbf{3}$ & $\mathbf{4}$ & $\mathbf{5}$ & $\mathbf{6}$ \\
\hline \hline 1 & 1.000 & 0.023 & 0.012 & 0.028 & 0.056 & 0.035 \\
\hline 2 & 0.023 & 1.000 & 0.043 & 0.057 & 0.018 & 0.017 \\
\hline 3 & 0.012 & 0.043 & 1.000 & 0.024 & 0.085 & 0.029 \\
\hline 4 & 0.028 & 0.057 & 0.024 & 1.000 & 0.052 & 0.017 \\
\hline 5 & 0.056 & 0.018 & 0.085 & 0.052 & 1.000 & 0.056 \\
\hline 6 & 0.035 & 0.017 & 0.029 & 0.017 & 0.056 & 1.000 \\
\hline
\end{tabular}

From Table $\mathbf{2}$ and Fig. (5), it is indicated that relative error between experiment modal frequency and finite element modal frequency stays within $10 \%$, and the maximum is $8.12 \%$ and that the vibration modes display good coincidence. Due to this, such finite element model is of acceptable precision for the dynamic analysis on enclosed gear-driven system in the engineering application.

\section{EXTENSIVE APPLICATION FOR FEM MODEL}

\subsection{Finite Element Dynamic Simulation}

\subsubsection{Nonlinear Factors}

In dynamic analysis, nonlinear factors mainly include time-varying mesh stiffness, composite mesh error, gear backlash, and damping ratio etc. Herein, stiffness and damping ratio cause parametric excitation, and error and backlash give rise to displacement excitation. These nonlinear parameters can be applied in ANSYS in the form of constant or curve, and the simulating process is made by virtue of 3D impact dynamics contact finite element mixing method [17].

\subsubsection{Time-Varying Mesh Stiffness}

Time-varying mesh stiffness, including average mesh stiffness and variable stiffness, can be expressed by: $\left\{\begin{array}{l}k_{s p i}(t)=k_{m s i}+k_{a s i} \cos \left(\omega t+\varphi_{s p i}\right) \\ k_{r p i}(t)=k_{m r i}+k_{a r i} \cos \left(\omega t+\varphi_{r p i}\right)\end{array}\right.$

where, $k_{s p i}$ and $k_{r p i}$ respectively refer to time-varying mesh stiffness of sun gear to $i^{\text {th }}$ planet gear and gear ring to $i$ th planet gear, $k_{m s i}$ and $k_{m r i}$ respectively refer to average mesh stiffness of sun gear to $i^{\text {th }}$ planet gear and gear ring to $i$ th planet gear, $k_{a s i}$ and $k_{a r i}$ respectively refer to stiffness variation of sun gear to $i^{\text {th }}$ planet gear and gear ring to $i$ th planet gear, and $\varphi_{s p i}$ and $\varphi_{r p i}$ respectively refer to initial phase of sun gear to $i$ th planet gear and gear ring to $i^{\text {th }}$ planet gear. Of which, $t$ indicates time, and $\omega$ indicates gear-mesh frequency calculated by planet gear drive:

$\omega=\frac{\omega_{s} z_{s} z_{r}}{z_{s}+z_{r}}$

where, $\omega_{s}$ denotes sun gear rotating speed, $z_{s}$ and $z_{r}$ respectively refer to tooth number of sun gear and gear ring.

\subsubsection{Composite Mesh Error}

Composite mesh error mainly results from gear pair static transmission error, sun gear and gear ring eccentric error, planet gear position error etc. To facilitate the study, we ignore planet gear position error here. All errors, after being projected along the engagement line's direction, are superposed into gear composite error.

Mesh static transmission error between sun gear/gear ring and $i$ th planet gear, namely, $e_{s p i}^{\prime}$ and $e_{r p i}^{\prime}$, can be expressed by:

$\left\{\begin{array}{l}e_{s p i}^{\prime}(t)=A_{s p i} \cos \left(\omega t+\beta_{s i}\right) \\ e_{r p i}^{\prime}(t)=A_{p p i} \cos \left(\omega t+\beta_{r i}+\gamma_{s s}\right)\end{array}\right.$

where, $A_{s p i}$ and $A_{r p i}$ respectively refer to the transmission error amplitudes of the gear pairs between sun gear/gear ring and the $i^{\text {th }}$ planet gear, and $\beta_{s i}$ and $\beta_{r i}$ respectively refer to the initial phase of static transmission error variation for inner and outer mesh gear pairs (see the reference [18]), and it is calculated according to the tooth number and planet gear's position angle.

After projecting the sun gear and gear ring's eccentric error $E_{s}$ and $E_{r}$, along the engagement line direction, we can obtain:

$$
\left\{\begin{array}{l}
E_{s} \cos \varphi_{s}=E_{s} \sin \left(\omega_{w} t+\eta_{s}-\frac{2 \pi}{N}(i-1)+\alpha\right) \\
E_{r} \sin \varphi_{r}=-E_{r} \sin \left(\omega_{n} t+\eta_{r}-\frac{2 \pi}{N}(i-1)+\alpha\right)
\end{array}\right.
$$

where $\varphi_{s}$ and $\varphi_{r}$ are respectively the included angles along the inner and outer engagement line's direction between sun gear/gear ring eccentric error and the $i$ th planet gear; $\eta_{s}$ and $\eta_{r}$ are respectively the initial phase of the sun gear/gear ring eccentric error variation; $\alpha$ refer to the gear pressure angle; $N$ stands for number of planet gear. $\omega_{s c}=\omega_{s}-\omega_{c}$, and $\omega_{r c}=\omega_{s c} \cdot z_{r} / z_{s}$, are respectively the rotating speed difference between the sun gear and planet carrier, and between the gear ring and the planet carrier; $\omega_{c}$ refer to planet carrier rotating speed. 
After consolidating Formula (3) and Formula (4), we can calculate composite mesh error of the sun gear/gear ring to the $i^{\text {th }}$ planet gear, namely $e_{s p i}$ and $e_{r p i}$, according to formula below:

$$
\left\{\begin{array}{l}
e_{s p i}(t)=A_{s p i} \cos \left(\omega t+\beta_{s i}\right)+E_{s} \sin \left(\omega_{s c} t+\eta_{s}-\frac{2 \pi}{N}(i-1)+\alpha\right) \\
e_{r p i}(t)=A_{r i} \cos \left(\omega t+\beta_{r i}\right)-E_{r} \sin \left(\omega_{r c} t+\eta_{r}-\frac{2 \pi}{N}(i-1)+\alpha\right)
\end{array}\right.
$$

\subsubsection{Backlash Nonlinear Function}

Existence of gear backlash will result in disengaging phenomenon during the gear meshing process, which will bring about repeated impact excitation on the system [19]. The said phenomenon can be expressed in the function formula below:

$$
f(X, b)= \begin{cases}X-b & X>b \\ 0 & -b \leq X \leq b \\ X+b & X<-b\end{cases}
$$

where, $X$ represents gear pair meshing point's relative displacement; $b$ refer to semi-backlash. As far as this system is concerned, gear ring is fixed onto the frame, and relative displacement of internal and external meshing points can be expressed as:

$$
\left\{\begin{array}{l}
X_{s p i}=x_{s}-x_{p i}-x_{c}-e_{s p i} \\
X_{r p i}=x_{p i}-x_{c}-e_{r p i}
\end{array}\right.
$$

where, $X_{s p i}$ and $X_{r p i}$ denote the relative displacement between sun gear/gear ring and the $i^{\text {th }}$ planet gear at the meshing point; $x_{s}, x_{p i}$, and $x_{c}$ respectively stand for sun gear, $i^{\text {th }}$ planet gear, and planet carrier linear displacements' projection along the engagement line.

\subsubsection{Damping Ratio}

Smaller damping ratio means more prominent nonlinearity, or vice versa, and damping ratio variation will exert serious influence on the system's dynamic response [20]. Damping ratio can be expressed by means of inner and outer gearing damping coefficients, $c_{s p i}$ and $c_{r p i}$, as follows:

$$
\left\{\begin{array}{l}
c_{s p i}=2 \zeta_{o} \sqrt{\frac{k_{m s i}}{1 / m_{s j}+1 / m_{p j i}}} \\
c_{r p i}=2 \zeta_{i} \sqrt{\frac{k_{m r i}}{1 / m_{r j}+1 / m_{p j i}}}
\end{array}\right.
$$

where, $\zeta_{i}$ and $\zeta_{o}$ respectively refer to gear pair inner/outer meshing damping ratio; $m_{s j}, m_{p j i}$ and $m_{r j}$ stand for mass of sun gear, planet gear, and gear ring's respectively $(j$ denotes $j^{\text {th }}$ stage and $i$ denotes $i^{\text {th }}$ planet gear).

\subsubsection{Finite Element Dynamic Calculation}

By using the ANSYS software, we can capitalize on the transient dynamics analysis to determine the structure's time-varying displacement, strain, stress, and force responding to steady loading, transient loading, harmonic loading and other types of loads, particularly taking into account the inertial force and damping force. To fulfill this
FE stimulation, full method of transient dynamic analysis in ANSYS is adopted

See Table 3 for the studied object's design data. Contact pair definition and constrain in FE model, respectively, coincides with that in modal analysis and in experiment. In FE stimulating, we exert rotating speed of $1470 \mathrm{rpm}$ onto the input end, together with data in Table 3 and relevant nonlinear parameters presented in Section 5.1.1 for ANSYS solving. After the calculation, we extract the time-domain acceleration data for the first and second stage rings making comparison with the results from experiment (see Fig. 8).

Table 3. Studied gear parameters.

\begin{tabular}{|c|c|c|c|}
\hline Gear Parameter & Value & Gear Parameter & Value \\
\hline \hline$\alpha /^{\circ}$ & 20 & $N$ & 3 \\
\hline$A_{s p i}=A_{\mathrm{rpi}} / \mu \mathrm{m}$ & 10 & $k_{\mathrm{msi}} / \mathrm{GN} / \mathrm{m}$ & 0.823 \\
\hline$E_{\mathrm{s}} / \mu \mathrm{m}$ & 25 & $k_{\mathrm{mri}} / \mathrm{GN} / \mathrm{m}$ & 1.0 \\
\hline$E_{\mathrm{r}} / \mu \mathrm{m}$ & 30 & $\zeta_{\mathrm{i}}=\zeta_{\mathrm{o}}$ & 0.07 \\
\hline$z_{\mathrm{s} 1}$ & 19 & $m_{\mathrm{s} 1} / \mathrm{kg}$ & 7 \\
\hline$z_{\mathrm{pli}}$ & 36 & $m_{\mathrm{pli}} / \mathrm{kg}$ & 10.9 \\
\hline$z_{\mathrm{r} 1}$ & 92 & $m_{\mathrm{c1} 1} / \mathrm{kg}$ & 52.2 \\
\hline$z_{\mathrm{s} 2}$ & 20 & $m_{\mathrm{s} 2} / \mathrm{kg}$ & 20.2 \\
\hline$z_{\mathrm{p} 2 \mathrm{i}}$ & 19 & $m_{\mathrm{p} 2} / \mathrm{kg}$ & 11.5 \\
\hline$z_{\mathrm{r} 2}$ & 58 & $m_{\mathrm{c} 2} / \mathrm{kg}$ & 129.3 \\
\hline$b_{\mathrm{spi}}=b_{\mathrm{rp}} / \mu \mathrm{m}$ & 10 & $m_{\mathrm{r}} / \mathrm{kg}$ & 229 \\
\hline$r_{\mathrm{input}} / \mathrm{rpm}$ & 1470 & $r_{\text {output }} / \mathrm{rpm}$ & 64.52 \\
\hline$m_{1}$ & 5 & $m_{2}$ & 8 \\
\hline
\end{tabular}

( $m_{i}$ refer to the $i^{\text {th }}$ planet gear drive system's gear module)

\subsection{Bench Dynamic Test}

In bench test, we make sure that assembling body's mounting state and running conditions, etc. are in full accordance with that in finite element dynamic simulation [21]. In this test, 9 measuring points are sampled, of which, point 1 is the drive motor's junction box part, point 2 is bearing end cover at the input end, point 3 is bearing (radial) at the input end, point 4 is the $1^{\text {st }}$ stage gear ring (radial), point 5 is the $2^{\text {nd }}$ stage gear ring (radial), point 6 is the fixing bench, point 7 is the mounting base, point 8 is the bearing end cover at the output end, and point 9 is the bearing (radial) at the output end. Each of the measuring points is equipped with three-way acceleration sensor, of which, Xcoordinate is used for measuring reducer's axial direction, Ycoordinate is used for measuring tangent direction (turning direction), and Z-coordinate is used for measuring the radial direction. See Fig. (6a) for sensor mounting, Fig. (6b) for positions of measuring points on reducer and Fig. (7) for measuring points $1,6,7$ and data acquisition, and bench test field. In this paper, we only make a comparison between the measured value along Y-direction of points 4 and 5 (see Fig. 6b) and finite element analysis results.

After the power is switched on, the motor will drive the reducer to work, enabling rotating speed of $1470 \mathrm{rpm}$ and sampling frequency of $512 \mathrm{~Hz}$. 
(a)

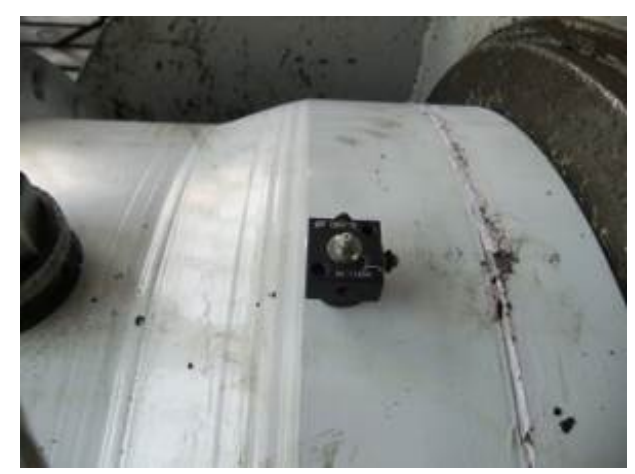

(b)

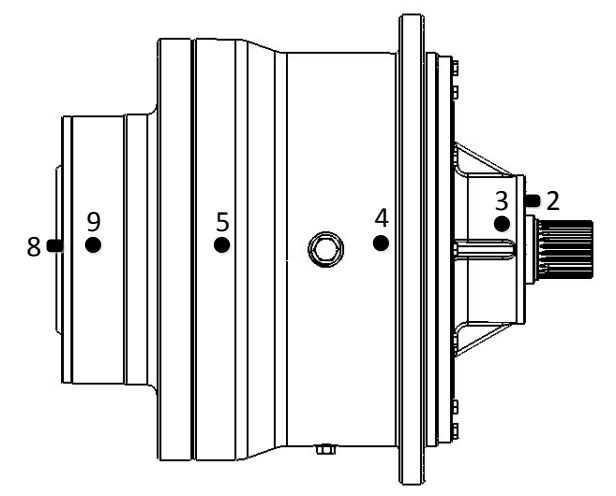

Fig. (6). Measuring points of dynamic simulation test. (a) Threeway acceleration sensor. (b) Measuring point's position sketch.

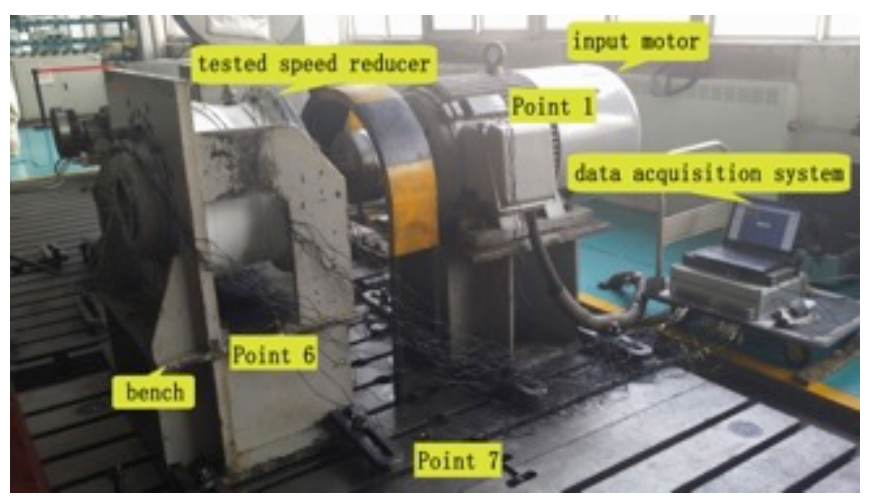

Fig. (7). Dynamic simulation test system.

\subsection{RESULT AND DISCUSSION}

The vibration acceleration data is collected along the $\mathrm{Y}$ direction of Point 4 and Point 5 within a time span of $0.1 \mathrm{~s}$ when the reducer is running steadily. And then a comparison is made between the measuring data and finite element simulation data. See Fig. (8).

Judging from Fig. (8) we can observe that there is a minor difference between simulation value and test value within $0.1 \mathrm{~s}$. In Fig. (8a), the test values fluctuate from -4 $\mathrm{m} / \mathrm{s}^{2}$ to $3 \mathrm{~m} / \mathrm{s}^{2}$, and the simulation values vary from $-2 \mathrm{~m} / \mathrm{s}^{2}$ to $2 \mathrm{~m} / \mathrm{s}^{2}$, both of which hover around the mean value -1 $\mathrm{m} / \mathrm{s}^{2}$. In Fig. (8b), the test values vary between $-3 \mathrm{~m} / \mathrm{s}^{2}$ and 2 $\mathrm{m} / \mathrm{s}^{2}$ and the simulation values fluctuate between $-1.5 \mathrm{~m} / \mathrm{s}^{2}$ and $1 \mathrm{~m} / \mathrm{s}^{2}$, both of which hover around the mean value (a)

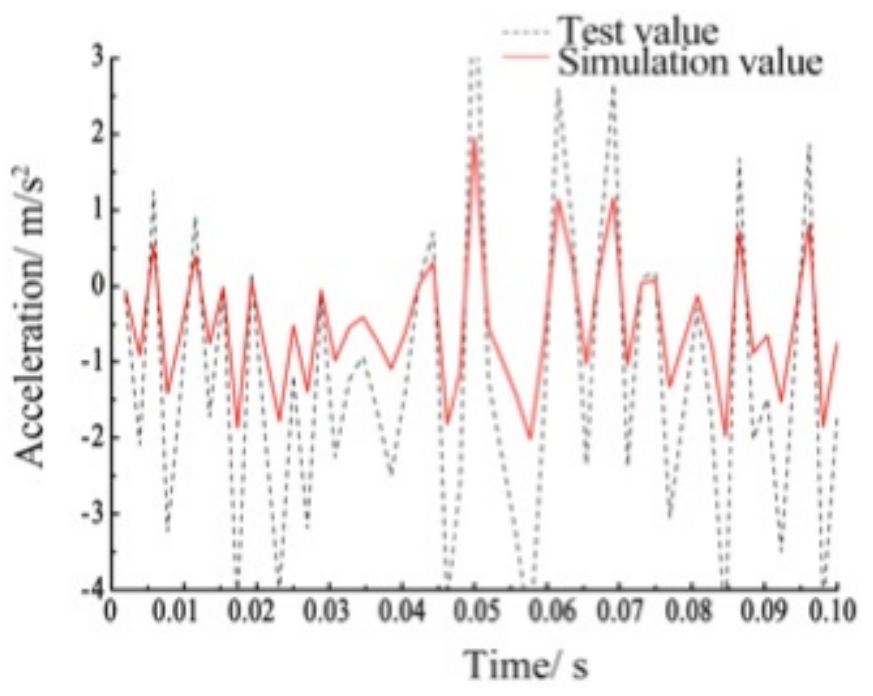

(b)

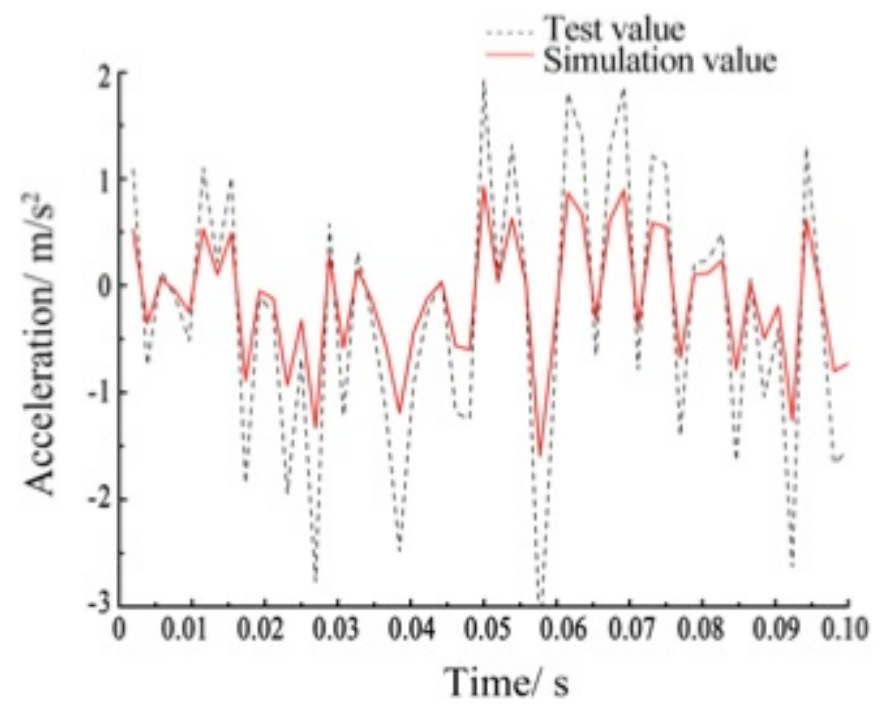

Fig. (8). Comparison between test and simulation acceleration value of measuring points 4 and 5. (a) Point 4. (b) Point 5.

$-0.5 \mathrm{~m} / \mathrm{s}^{2}$. Test values and simulation values basically have the same vibrational tendency and the mean value errors are relatively small. The errors result mostly from relatively high environmental noise during the test, such as noise and vibrations by running motor, etc. However, the simulating environment is an ideal state in which there are no interferences from outside. Thereby, it's feasible, on the whole, to perform dynamic simulation to the secondary planet reducer by using proposed finite element method.

\subsection{Acquisition of Internal Dynamic Response}

As for verified finite element model, we prolong the simulation time to $1 \mathrm{~s}$ while keeping its simulation parameters unchanged. Since sun gear in $1^{\text {st }}$ stage and planet carrier in $2^{\text {nd }}$ stage, respectively, serve as the entire system's input end and output end, their vibration state are of typical significance in the analysis of the system's dynamic characteristics. For this reason, we take their vibration acceleration curves for analysis. See Fig. (9). 
(a)

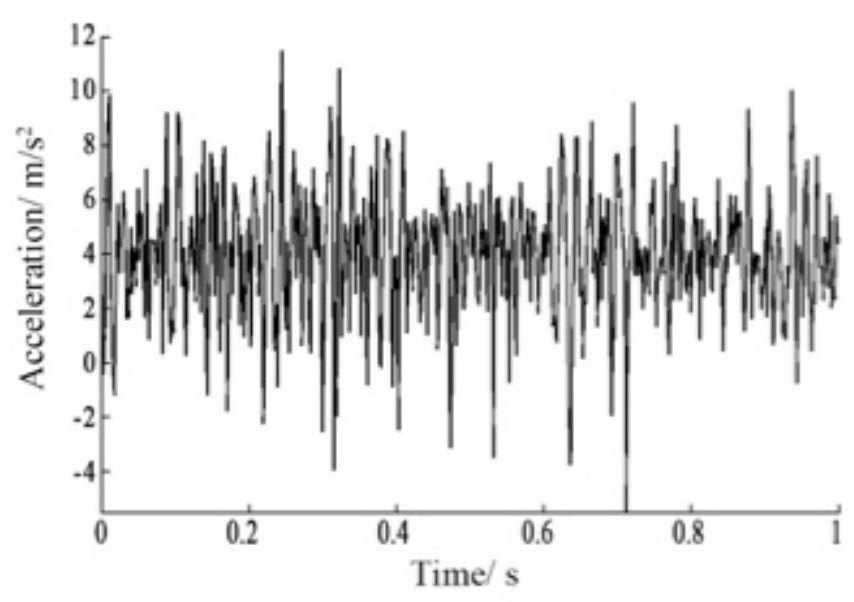

(b)

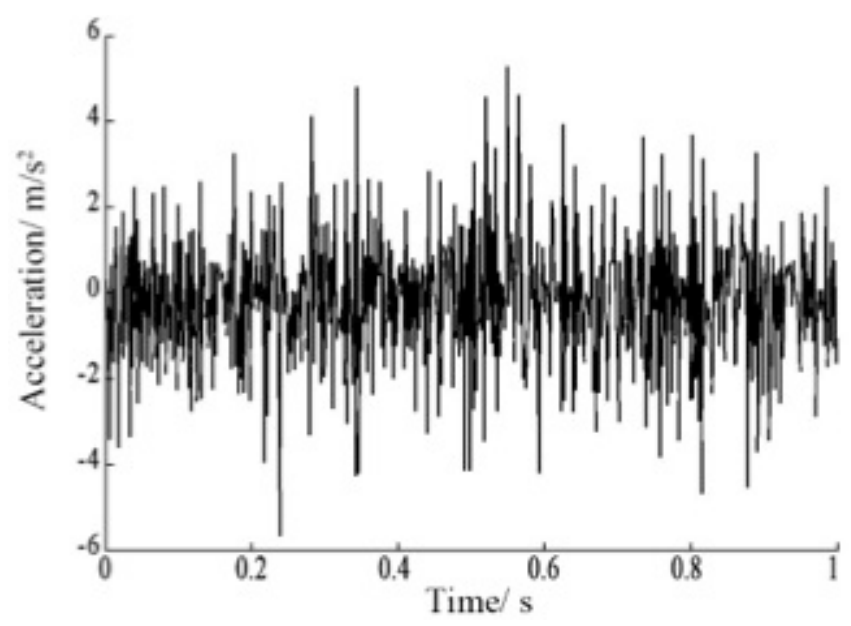

Fig. (9). Accelerations of input and output ends. (a) Vibration acceleration of the input end. (b) Vibration acceleration of the output end.

Judging from the above figure, we can see that due to existence of nonlinearity factor, vibration acceleration curves of the input and output ends take on typical nonlinearity traits. Vibration acceleration of the input end varies between $-5 \mathrm{~m} / \mathrm{s}^{2}$ and $12 \mathrm{~m} / \mathrm{s}^{2}$, and that of the output end fluctuates between $-6 \mathrm{~m} / \mathrm{s}^{2}$ and $6 \mathrm{~m} / \mathrm{s}^{2}$. To sum up, vibration of the input end is more intensive as compared to that of output end. That should be attributed to the cause below: during dynamic test, sun gear in the $1^{\text {st }}$ stage is directly driven by the motor spindle through spline connection, so its vibration amplitude is approximate to that of the motor spindle's end, which is the main power source. The $2^{\text {nd }}$ stage is no-load output end undergoing lower rotating speed and larger torque with long distance from the power source, so its vibration amplitude is comparatively low.

Moreover, stress curve from some point from gear ring surface after absolute meshing with time duration of $0.16 \mathrm{~s}$ is as shown in Fig. (10). It indicates that the stress variation accords with the practical case in which the stress reaches maximum value at the moment of meshing and decreases subsequently after meshing.

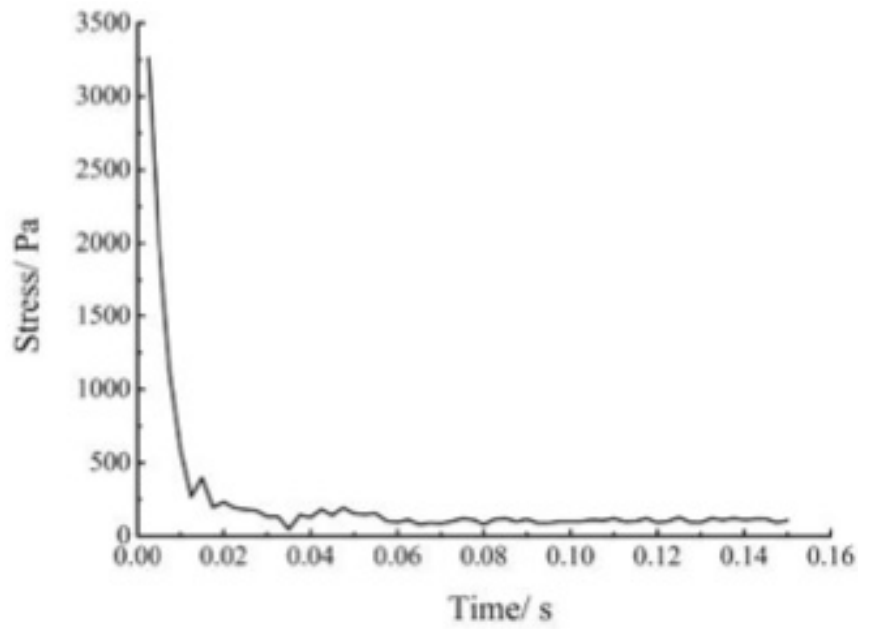

Fig. (10). Some point stress change curves on ring gear face.

\section{CONCLUSION}

In this paper, we capitalize on finite element method to perform secondary planet reducer dynamic simulation, in which we take into account those nonlinear factors, such as time-varying mesh stiffness between gear pairs, composite mesh error, backlash, and mesh damping, etc., finding that the housing surface's dynamic simulation results and dynamic test are consistent.

\section{Major conclusion:}

(1) The model is created precisely with Solidworks software. To streamline the analysis, minor nodes are left out, for example, chamfering, circular bead, aperture, clearance groove, tool withdrawal groove, retainer ring, and seal ring etc. When assembling, advanced mechanical fitting mode is adopted for the gear meshing, in addition to verifying the model's correctness from the perspective of size, mass, and kinematics characteristics.

(2) The finite element model is created according to 3D model. In grid partitioning, the drive gear tooth profile is divided precisely so as to strike a balance between precision and efficiency. As for stationary parts like the support part and the end cap, the grids are partitioned in a moderate density, and rational contact relation is set.

(3) Finite element modal calculation and test modal analysis and comparison are carried out on a reducer assembling body. Finding that the natural frequency values are quite close and the modes of vibration coincide with one another, by which correctness of the finite element model is verified.

(4) Dynamic simulation is performed on the reducer assembling body, and bench dynamic vibration test is made for vibration acceleration curves of stage- 1 and stage-2 gear rings, finding that the trends are consistent. Due to environmental factors, there are only minor differences in vibration acceleration values. That implies the finite element dynamic simulation method is feasible and of reliable precision. Based on this, vibration acceleration curves 
of the input end and output end are taken for analysis. In the entire experimental process, drive motor serves as the main vibration source and stage-1 sun gear is driven by the motor, so its vibration amplitude is equivalent to the motor vibration amplitude. In addition, the output end is free load and has a relatively long distance from the vibration source, so its vibration amplitude value is relatively smaller as compared to the input end. Therefore, the analysis results coincide with the actual results.

(5) Consistency between finite element simulation results and bench test results fully verifies the finite element method's efficiency and feasibility, so it can be used in performing analysis on internal dynamic response. Also, this method offers theoretical foundation for making dynamic analysis on enclosed gear-driven system, diagnosing the system's faults, and alleviating its vibration and reducing the noise.

\section{CONFLICT OF INTEREST}

The authors confirm that this article content has no conflict of interest.

\section{ACKNOWLEDGEMENTS}

This work was supported by the National Science Foundation for Young Scientists of China (Grant no. 51305288), the Scientific Research Foundation for Overseas Returnee of Shanxi Province (Grant no. 2012-073), and the Science Foundation for Young Science And Technology Research of Shanxi Provincial (Grant no.2013021020-1).

\section{REFERENCES}

[1] L. Faydor, F. Alfonso, and H. Kenichi, "Design manufacture stress analysis and experimental tests of low-noise high endurance spiral bevel gears", Mechanism and Machine Theory, vol. 41, pp. 83-118, Jan. 2006.

[2] X. R. Xia, F. J. Yang, and C. J. Meng, "Influences of hypoid gear quality on rear axle noise", Journal of Hefei University of Technology (Natural Science), vol. 32, pp. 167-170, 2009.

[3] J. Zhang, S. L. Xie, P. M. Xu, and B. H. Tong, "Elasto-statics analysis of spider reducer with small tooth number difference", Transactions of the Chinese Society of Agricultural Engineering (Transactions of the CSAE), vol. 29, no. 24, pp. 49-55, Dec. 2013.

[4] Z. M. Xu, F. Y. Shi, H. Yansong, H. D. Peng, and W. L. Zhou, "Simulation on heat transfer characteristics of vehicle wheel reductor", Transactions of the CSAE, vol. 27, no. 4, pp. 158-163, 2011.

[5] H. N. Ozguven, and D. R. Houser, "Mathematical models used in gear dynamics-a review", Journal of Sound and Vibration, vol. 121, no. 3, pp. 383-411, 1988.
[6] K. Zoltan, S. A. Resita, and C. Platforma, "An Overview of Mathematical Models Used in Gear Dynamics", RJAV, vol. 4, no. 1, pp. 43-50, 2007.

[7] F. Z. Li, S. G. Tong, and X. B. Wang, "Dynamic Optimization Design for Working Device of Hydraulic Excavator Based on Modal Analysis", Transactions of the Chinese Society for Agricultural Machinery, vol. 45, no. 4, pp. 28-36, 2014.

[8] A. Kahrarman, "Free torsional vibration characteris tics of compound planetary gear sets", Mech. Mach. Theory, vol. 36, no. 8, pp. 953-971, 2001.

[9] J. H. Lu, R. P. Zhu, and G. H. Jin, "Analysis of dynamic load sharing behavior in planetary gearing", Journal of Mechanical Engineering, vol. 45, no. 5, pp. 85-90, 2009.

[10] Z. M. Xiao, D. T. Qin, J. H. Wang, W. H. Wu, and L. F. Chen, "Study on torsional dynamics of 3-stage planetary gears of main reducer used in driving cutterhead of shield tunnelling machine", China Mechanical Engineering, vol.21, no.18, pp. 2176-2182, 2010.

[11] T. J. Li, R. P. Zhu, H. Y. Bao, C. L. Xiang, and H. Liu, "Nonlinear torsional vibration modeling and bifurcation characteristic study of a planetary gear train", Chinese Journal of Mechanical Engineering, vol. 47, no. 21, pp. 76-83, 2011.

[12] N. C. Guo, W. K. Shi, W. J. Liu, R. S. Rong, and Z. C. Xu, "Dynamic finite element simulation for driving axle", Journal of Xi'an Jiaotong University, vol. 36, no. 9, pp. 91-95, 2012.

[13] J. J. Yang, X. J. Zhou, Y. D. Wei, and R. Gong, "Test bed modeling and control method for track vehicle", Transactions of the Chinese Society for Agricultural Machinery, vol. 44, no. 6, pp. 8-13, 2013.

[14] Z. H. Tang, Q. D. Yan, and S. H. Leng, "CAA technology for planetary transmission", Transactions of the Chinese Society for Agricultural Machinery, vol. 43, no. 10, pp. 14-18, 2012.

[15] J. Liu, J. L. Gao, W. L. Xie, Y. Xu, J. D. Meng, and Y. C. Liao, "Design and application of the experimental model analysis system", Transactions of the Chinese Society for Agricultural Machinery, vol. 40, no. 2, pp. 209-213, 2009.

[16] J. Wang, H. X. Pan, and X. B. Yang, "Modal analysis of gearbox based on the method of PolyMAX", Journal of Mechanical Transmission, vol. 37, no. 2, pp. 66-69, 2013

[17] T. J. Lin, R. K. Jiang, R. F. Li, and X. S. Du, "Vibration analysis and noise evaluation of coaxial planetary gear reducer with dua power output", Journal of Chongqing University Natural Science, vol. 30, no. 11, pp. 1-4, 2007.

[18] R. Li, and J. Wang, Dynamics of Gear System: Vibration, Shock and Noise. Beijing Science Press 1997.

[19] Z. H. Bu, G. Liu, and L. Y. Wu, "Research advances in planetary gear trains dynamics", Journal of Vibration and Shock, vol. 29, no 9, pp. 161-166, 2010.

[20] L. H. Wang, R. F. Li, Te. J. Lin, and C. Y. Yang, "Research on nonlinear vibration characteristics due to time-varying mesh stiffness and gear backlash in gear system", China Mechanical Engineering, vol. 14, no. 13, pp. 69-72, 2003.

[21] X. L. Zhang, D. Pan, S. Jiang, B. Chen, and C. M. Cao, "Experiment on real-time test method for automotive suspension distance based on acceleration", Transactions of the Chinese Society for Agricultural Machinery, vol. 44, no. 10, pp. 15-22, 2013. 